\title{
Research of Reactive Power Planning Optimization Based on Improved Adaptive Genetic Algorithm for Wind Power Plant
}

\author{
Shijie Liu \\ College of Mechanical and Electrical Engineering, Agricultural University of Hebei, Baoding 071001, China
}

\begin{abstract}
Contrapose the randomness of wind speed and the wind power, use the method of multi-scenario based on probability analysis to study reactive power planning of wind power system and make the multi-scenario expectation model. On this basis, use improved adaptive genetic algorithm with subsection self-adaption selection strategy and the continuous changing mutation probability calculation method. Algorithm stability has been improved. The convergence of generation number has been reduced. And global optimization ability has been improved. The analysis of examples has verified the correctness and effectiveness of the model and the algorithm.
\end{abstract}

Keywords-wind power plant; multi-scenario modeling; reactive power planning optimization; improved adaptive genetic algorithm

\section{INTRODUCTION}

Wind power general access to the end of the distribution network, is the weak link of the structure part of the grid, power generation with fluctuation and randomness, the lack of reactive power will cause changes in the grid voltage, serious when can cause the collapse of the power system [1]. Reactive power optimization can reduce wind electric field effects on power system voltage stability, when necessary, can offer effective reactive power support to the grid voltage of wind power plant [2].

Based on the probabilistic analysis method [3] and the improved adaptive genetic algorithm, this dissertation improves the convergence precision of the genetic algorithm and accelerates the convergence rate.

\section{Multi-scenario Modeling OF Wind Power Plant REACTIVE POWER PlanNing OptiMIZATION}

In view of the randomness of wind power output, a scenario method based on probability analysis is used to study the optimization of reactive power planning of wind farm. According to the wind power plant installed capacity accounted for the proportion, divided into 10 scenes interval. There are $[0 \sim 10),[10 \sim 20),[20 \sim 30),[30 \sim 40),[40 \sim 50)$, $[50 \sim 60), \quad[60 \sim 70), \quad[70 \sim 80), \quad[80 \sim 90), \quad[90 \sim 100)$ respectively. Through scenario analysis, the establishment of wind power plant network loss expected value programming model.

\section{A. Objective Function}

The expectations of the most common stochastic planning value planning [4]used to built wind farm loss expected value programming model to realize the integration of multi objectives. The annual wind farm network loss cost and the minimum investment expected value of the reactive power compensation device as objective function:

$$
\begin{gathered}
\min F=C_{1}\left(E\left(P_{\text {loss }}\right)\right)+C_{2}(Q) \\
\text { among: }\left\{\begin{array}{l}
C_{1}\left(E\left(P_{\text {loss }}\right)\right)=C_{p}\left(\sum_{i=1}^{N_{s}} T_{s} k_{i} p_{s}^{i}\right) \\
C_{2}(Q)=\left[\left(C_{q 1} \sum_{j=1}^{N_{q}} \tau_{j}+C_{q 2} \sum_{j=1}^{N_{q}}\left(\tau_{j} * Q_{c j}\right)\right] / Y\right.
\end{array}\right.
\end{gathered}
$$

In the arithmetic formula, the $p_{s}^{i}$ expressed network loss calculation based on power flow in the $i$ scenario of wind power plant value obtained. The $T_{s}$ expressed the hours of wind power plant of operating a year. The $k_{i}$ expressed the probability distribution of the corresponding value of the $i$ scene. The $N_{s}$ expressed the number of scenes. The $C_{p}$ is electrovalence. The $C_{q 1}$ is reactive power compensation equipment units compensation point of investment funds. The $C_{q 2}$ is the installation and maintenance costs of reactive power compensation equipment unit capacity. The $Q_{c j}$ is node reactive power compensation capacity of the $j$ node. The $\tau_{j}$ is reactive power compensation device of reactive power compensation whether is put into use the $j$ candidate node(Put into use is 1, do not put into use is 0 ). The $N_{q}$ is the number of candidate points compensation. The $Y$ is the life of reactive power compensation equipment.

\section{B. Equality and Inequality Constraints}

Power flow equations is:

$$
\left\{\begin{array}{l}
P_{G i}-P_{L i}=U_{i} \sum_{j=1}^{N} U_{j}\left(G_{i j} \cos \theta_{i j}+B_{i j} \sin \theta_{i j}\right) \\
Q_{G i}+Q_{C i}-Q_{L i}=U_{i} \sum_{j=1}^{N} U_{j}\left(G_{i j} \sin \theta_{i j}-B_{i j} \cos \theta_{i j}\right)
\end{array}\right.
$$

In the arithmetic formula, $P_{G i}$ and $P_{L i}$ is active power and active load of the $i$ node wind turbine. $Q_{G i}, Q_{C i}$ and 
$Q_{L i}$ is reactive power, reactive power compensation device of reactive power compensation and reactive load of the $i$ node wind turbine. $U_{i}$ and $U_{j}$ is the voltage value of node $i$ and node $j$. The $G_{i j}$ is the node conductance between node $i$ and node $j$. The $B_{i j}$ is the node susceptance between node $i$ and node $j$. The $\theta_{i j}$ is phase angle difference between the node $i$ and node $j$. The $N$ is the total number of nodes.

For inequality constraints, all control variables and state variables should satisfy the upper and lower constraints.

\section{IMPROVED ADAPTIVE GENETIC ALGORITHM}

\section{A. Code}

Wind power plant without reactive power compensation device type and the voltage class is known in advance, using the mapping method [5], the different levels of non reactive power compensation equipment capacity and investment cost mapping to continuous integer variable space, using decimal integer coding, improve the efficiency of genetic manipulation. In order to simplify, the dissertation used SVC instead of reactive power compensation device. Table I is coding scheme of SVC.

TABLE I. CODING SCHEME OF SVC

\begin{tabular}{cccccccccccc}
\hline Code & 1 & 2 & 3 & 4 & 5 & 6 & 7 & 8 & 9 & 10 & $\cdots$ \\
\hline $\begin{array}{c}\text { Cap- } \\
\text { acity } \\
\text { (Mvar) }\end{array}$ & 1 & 3 & 5 & 6.5 & 9.6 & 12 & 16.8 & 19.2 & 30 & 41.2 & \\
\hline
\end{tabular}

The control variables as shown in formula (5), the $\tau_{i}$ is alternate reactive power compensation switching state of $i$. The $Q_{i}$ is compensation capacity of node $i$. The $N_{q}$ is alternate total reactive power compensation.

$$
X=\{\tau \mid Q\}=\left\{\tau_{1}, \tau_{2} \cdots \tau_{N_{q}} \mid Q_{1}, Q_{2} \cdots Q_{N_{q}}\right\}
$$

\section{B. The Establisher of Fitness Function}

In this dissertation, the objective function value obtained by scaling by simulated annealing [6],made the algorithm has better convergence speed and convergence precision. Fitness scaling algorithm expressed as:

$$
f=\exp \left[\frac{1}{K F}\right]
$$

among:

$$
K= \begin{cases}T & N_{g e n}<N_{\text {Mgen }} / 2 \\ T * 0.99^{\text {Ngen }} & N_{\text {gen }}>N_{\text {Mgen }} / 2\end{cases}
$$

In the arithmetic formula, the $f$ is Objective function value. The $F$ is the individual fitness function value. The $T$ is the initial temperature of simulated annealing. The $N_{\text {Mgen }}$ is maximum evolutionary algebra. The $N_{\text {gen }}$ is current evolutionary algebra.

\section{Balanced Regional Selection Strategy}

In order to make more excellent individuals into the crossover and mutation operation, the selection step to adopt a balanced regional strategy selection [7], The realization method for:

The total is divided into three stages of evolution algebra, The $N_{\text {Mgen }}$ is the maximum evolutionary algebra.

The second stage is $\left[0,1 / 3 N_{M g e n}\right)$. This stage as the initial stage of evolution, the individual diversity good, using random selection strategy, so that each individual is selected the same opportunity. In a certain extent can prevent oversights.

The first stage is [1/3 $N_{\text {Mgen }}, 2 / 3 N_{M g e n}$ ). The evolution of population to the stage, began to appear obvious individual difference. Now, suppose total number of individuals for L, according to the fitness degree from high to low in order for individual ranking, and then take out one of the former L / 4 the fitness of an individual is multiplied by the coefficient $f_{1} / f_{1 / 4}$, improve fitness make excellent individuals are more likely to be selected. The second stage is the choice of roulette method.

The third stage is(2/3 $N_{\text {Mgen }}, N_{\text {Mgen }}$ ]. The elitist strategy is a generation adaptation of individuals with greater probability of retention to the next generation and produced a generation of the best individual random replacement of a new generation to smaller individuals, improve the convergence speed of the algorithm.

\section{EXAMPLE ANALYSIS}

Composed of 28 units 2 MW doubly fed wind power generator wind power plant model (as shown in Figure I) is established in this dissertation, reactive power compensation device for the reunification of the SVC and wind motor according to the 9/10/9 arrangement form arrangement in the three $35 \mathrm{kV}$ lines, each typhoon motor are equipped with a $0.69 / 35 \mathrm{kV}$ box variable and SVC locations in the box becomes high side or on both sides of the main transformer, a total of 30 alternate compensation point. The wind motor node voltage limits were set to $1.1 \mathrm{pu}$ and $0.9 \mathrm{pu}$, the other node voltage bound for $1.07 \mathrm{pu}$ and $0.97 \mathrm{pu}$ respectively. Double fed wind generator with rated power factor control method, using SVC (constant voltage control target voltage is set to $1.01 \mathrm{pu}$ ). 


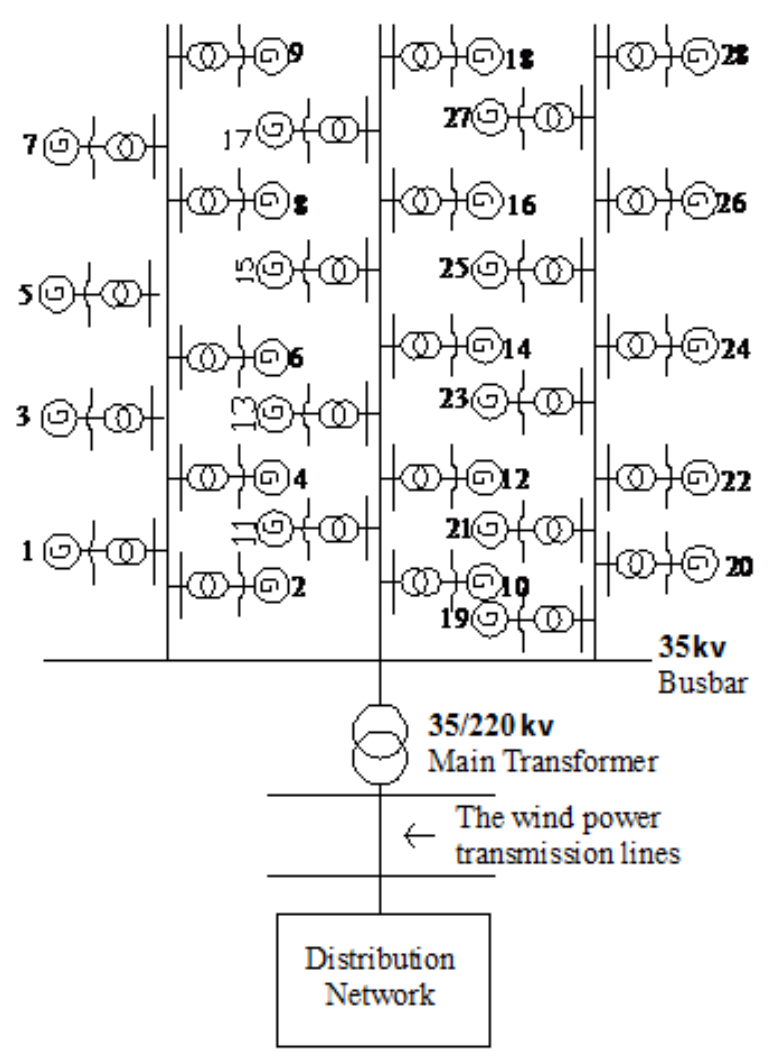

FIGURE I. WIND POWER PLANT MODEL

According to a probability distribution area of wind power plant under different working conditions in 10 scenarios are shown in Table II.

TABLE II. PROBABILITY DISTRIBUTION VALUE OF WIND GENERATOR IN EACH SCENARIO

\begin{tabular}{ccccccccccc}
\hline Scene & 1 & 2 & 3 & 4 & 5 & 6 & 7 & 8 & 9 & 10 \\
\hline Outpu & 0 & 10 & 20 & 30 & 40 & 50 & $60-$ & 70 & 80 & 90 \\
t & - & -2 & -3 & -4 & -5 & -6 & 70 & -8 & -9 & -1 \\
range & 1 & 0 & 0 & 0 & 0 & 0 & & 0 & 0 & 00 \\
(\%) & 0 & & & & & & & & & \\
Proba & 2 & & & & & & & & & \\
- & 7. & 10. & 7.8 & 5.9 & 5.1 & 4.2 & 5.8 & 5.1 & 4. & 23 \\
Bility & 3 & 23 & 1 & 8 & 2 & 1 & 2 & 2 & 64 & 5 \\
$(\%)$ & 2 & & & & & & & & &
\end{tabular}

The parameters of the objective function is: the price of 0.5 yuan $/ \mathrm{kW}-\mathrm{H}$; the annual operation of wind farm when the number is $8760 \mathrm{~h}$; SVC equipment cost is 100 thousand yuan /Mvar; compensation equipment installation and maintenance costs 10 thousand yuan. Genetic algorithm initial population size is set to 50 .

Using a standard adaptive genetic algorithm (AGA) and improved adaptive genetic algorithm used in this dissertation (IAGA) iscompared. AGA without using a piecewise adaptive selection strategy, continuously changing mutation probability strategy, other parameters and operation and IAGA, AGA minimum algebra is set to 100, IAGA minimum algebra is set to 30, 100 times calculated after two methods comparison results are shown in Table III shows, Table IV as one of the most excellent results.
TABLE III. STATISTICAL RESULT OF TWO KINDS OF ALGORITHM

\begin{tabular}{ccccccc}
\hline $\begin{array}{c}\text { Algorith } \\
\mathrm{m}\end{array}$ & $\begin{array}{c}\text { Minim } \\
\text { al } \\
\text { algebr } \\
\mathrm{a}\end{array}$ & $\begin{array}{c}\text { Maxim } \\
\text { al } \\
\text { algebra }\end{array}$ & $\begin{array}{c}\text { Avera } \\
\text { ge } \\
\text { algebr } \\
\mathrm{a}\end{array}$ & $\begin{array}{c}\text { Minimu } \\
\mathrm{m} \\
\text { cost(Te } \\
\mathrm{n} \\
\text { thousan } \\
\mathrm{d} \text { ) }\end{array}$ & $\begin{array}{c}\text { Maximu } \\
\mathrm{m} \\
\text { cost(Ten } \\
\text { thousan } \\
\mathrm{d})\end{array}$ & $\begin{array}{c}\text { Average } \\
\text { cost } \\
\text { (Ten } \\
\text { thousan } \\
\mathrm{d} \text { ) }\end{array}$ \\
\hline AGA & 100 & 176 & 137 & $\begin{array}{c}213.853 \\
1\end{array}$ & $\begin{array}{c}236.832 \\
1\end{array}$ & $\begin{array}{c}220.042 \\
6\end{array}$ \\
\hline IAGA & \multirow{2}{*}{48} & 120 & 74 & $\begin{array}{c}213.819 \\
2\end{array}$ & $\begin{array}{c}223.462 \\
4\end{array}$ & $\begin{array}{c}215.918 \\
8\end{array}$ \\
\hline
\end{tabular}

TABLE IV. THE BEST RESULT OF WIND POWER PLANT REACTIVE POWER PLANNING OPTIMIZATION

\begin{tabular}{|c|c|c|c|c|}
\hline $\begin{array}{c}\text { Optimized } \\
\text { installatio } \\
\text { n point }\end{array}$ & $\begin{array}{l}\text { Correspondin } \\
\text { g installation } \\
\text { point } \\
\text { compensation } \\
\text { capacity } \\
\text { (Mvar) }\end{array}$ & $\begin{array}{l}\text { Annual } \\
\text { cost of } \\
\text { total } \\
\text { invest- } \\
\text { ment in } \\
\text { the } \\
\text { device } \\
\text { (Ten } \\
\text { thousand } \\
\text { ) }\end{array}$ & $\begin{array}{c}\text { Annual } \\
\text { cost of } \\
\text { network } \\
\text { loss } \\
\text { expectation } \\
\mathrm{t} \\
\text { (Ten } \\
\text { thousand) }\end{array}$ & $\begin{array}{c}\text { Annual } \\
\text { comprehensiv } \\
\text { e cost } \\
\text { (Ten } \\
\text { thousand) }\end{array}$ \\
\hline $\begin{array}{c}1,11,12 \\
14,26\end{array}$ & $1,1,3,6.5,1$ & 4.3333 & 209.4859 & 213.8192 \\
\hline
\end{tabular}

The average objective function values with the two methods change the results shown in Figure II. Is shown in Figure II. AGA mean objective function values exhibit oscillatory trend, poor stability and at the same time, the algorithm to prematurely into the risk of premature convergence, and IAGA in the initial search ability strong, average objective function value constant oscillation, with the evolution of populations, mean decreases, in the late of stable convergence, taking into account the search and the stability of the algorithm.

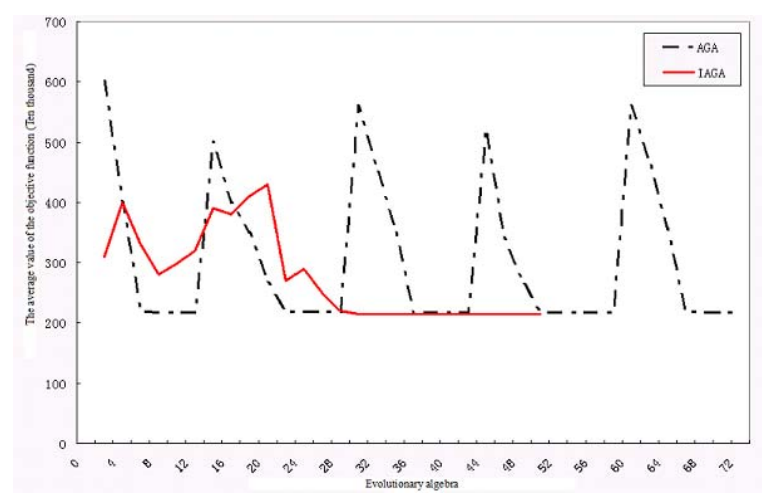

FIGURE II. THE AVERAGE OBJECTIVE FUNCTION VALUE COMPARISON OF TWO KINDS OF ALGORITHMS

\section{CONCLUSION}

According to the randomness of wind speed and wind power output, the use of reactive power planning based on multi scenario probability analysis methods of wind power system, and use the improved adaptive genetic algorithm in computing. The example analysis shows :

(1) through the establishment of multi scene expectation model, realizes the dynamic planning. 
(2) using an improved adaptive genetic algorithm, using piecewise adaptive selection strategy, continuous changing mutation probability calculation method and improve the algorithm stability, reduce the Algebraic Convergence and enhance the global searching ability, can effectively find the optimal reactive power compensation device installation location and installation capacity.

\section{ACKNOWLEDGMENT}

Foundation Project: Hebei Provincial Department of science and technology research subject (number: 12226509)

About the Author: Shijie Liu(1996-), man, Hengshui City,Hebei Province, undergraduate, Measurement and control technology and instrument specialty (726159485@qq.com)

\section{REFERENCE}

[1] Xiaoqun Ding, Ling Zhou, Guangyu Chen. Intelligent automatic voltage control (smart AVC) technology [M]. Beijing, China Machine Press, 2012.

[2] Hansen A D, Sorensen P, Iov F, et al. Control of variable pitch/variable speed wind turbine with doubly-fed induction generator[J]. Wind Eng. 2004, 28(9): 411-432.

[3] Peijin Liu, Lichen GU. Optimization of Reactive Power Planning for Power System Containing Wind Farms [J]. Power System Technology, 2010, 34(7): 175-180.

[4] Nan Xu. Research on Transmission Network Planning Considering Wind Farm Connected [D]. Beijing, North China Electric Power University, 2009.

[5] Ping Zhang. Research on Reactive Optimized Compensation for Wind Farms [D]. Changsha, Changsha University Of Science \& Technology, 2009.

[6] Keyan Liu, Wanxing SHENG, Yunhua LI. Research on Reactive Power Optimization Based on Improved Genetic Simulated Annealing Algorithm [J]. Power System Technology, 2007, 31 (3): 13-18.

[7] Siyan Wang. A New Study on the Self-adaptive Genetic Algorithm [D]. Hebei, North China Electric Power University, 2009. 